\title{
EDUCAÇÃO NÃO FORMAL COMO ENTE MAXIMIZADOR DAS POTENCIALIDADES DA EDUCAÇÃO FORMAL ${ }^{*}$
}

Bruno Inácio da Silva Pires

Carmen de Almeida Martins

São bem conhecidas as dificuldades de apreensão do contemporâneo. Afirma-se com frequência que só se pode obter e aproveitar o conhecimento sobre as coisas de alguma maneira acabada e encerrada. [...] Essa formulação baseia-se num sentido da separação inerente entre experiência e conhecimento, uma crença de que, quando experimentamos a vida, só podemos compreendê-la parcialmente e de que, quando tentamos compreender a vida, deixamos de experimentá-la de fato. De acordo com esse modelo, o ato de conhecer está sempre condenado a chegar tarde demais à cena da experiência. (Steven Connor, Cultura Pós-Moderna, 1993).

Cabe iniciar nossas reflexões acerca da relação museu-escola com a certeza de que o conhecimento deve ser aliado à experiência ou, além, à experimentação do novo, do curioso, do diferente que nos proporciona a visitação a museus. Porém, antes de adentrar a esta discussão, discorreremos sobre os índices educacionais brasileiros e como a Educação Básica pode potencializar a qualidade da educação com a visitação a museus e, para tanto, pautaremo-nos na perspectiva teórica de Pierre Bourdieu.

*DOI - 10.29388/978-65-86678-24-6-0-f.39-56 


\section{Introdução}

A Educação Básica pública no Brasil, que compreende da Educação Infantil até o $3^{\circ}$ ano do Ensino Médio, atualmente não tem revelado, para as avaliações em larga escala, altos índices de aprendizado/ proficiência no que se refere à eficácia do processo de ensino-aprendizagem. Esta afirmativa é embasada pelos últimos dados da Prova Brasil/SAEB e referendada pelo Programa Internacional de Avaliação de Estudantes (PISA), que abordaremos no decorrer de nossas discussões.

Quando analisamos tais dados estes nos levam a realizar discussões que relacionam, em uma ideia de complementaridade, a Educação Formal (EF) e a Não Formal (ENF): O que está acontecendo com o processo de ensino-aprendizagem de nossos alunos? Se a avaliação avalia não somente o discente, mas também o docente, está nosso professor preparado para, de fato, desempenhar sua função essencial de ensinar? Quais caminhos e/ou alternativas podemos ter para que o processo de aprendizagem não seja maçante e sem significado para nossos alunos? Como os docentes podem colaborar para que os estudantes tenham acesso a condições de capital cultural/social em uma sociedade excludente, visando à ascensão social e cultural por meio da escola?

O objetivo do presente texto é, primordialmente, discutir as possibilidades de ampliação cultural de nossos estudantes por meio da apropriação dos espaços de Educação Não Formal como, por exemplo, os museus, e possíveis impactos destes nos indicadores educacionais.

Autores como Leffa (1996), Dell Isolla (1996) e Goulemot (1996) concordam que a aprendizagem deve se basear na interação com o aluno, pela qual as experiências nos espaços de Educação For mal e de Educação Não Formal devem sempre ser levadas em consideração, para assim, atenderem às condições de construção de sentidos baseadas nas vivências cotidianas e em sua visão acerca da realidade 
que os rodeia. Quanto à potencialidade apresentada pela ENF, Gohn (2006, p. 2) pontua que:

A educação não-formal designa um processo com várias dimensões tais como: a aprendizagem política dos direitos dos indivíduos enquanto cidadãos; a capacitação dos indivíduos para o trabalho, por meio da aprendizagem de habilidades e/ou desenvolvimento de potencialidades; a aprendizagem e exercício de práticas que capacitam os indivíduos a se organizarem com objetivos comunitários, voltadas para a solução de problemas coletivos cotidianos; a aprendizagem de conteúdos que possibilitem aos indivíduos fazerem uma leitura do mundo do ponto de vista de compreensão do que se passa ao seu re dor; a educação desenvolvida na mídia e pela mídia, em especial a eletrônica.

Segundo Cazelli (1992) a ENF tem como um de seus objetivos a complementação da EF de modo a maximizar o processo de aprendizagem e desenvolver, juntamente com os espaços formais, as potencialidades daqueles que já passaram ou estão nos espaços formais.

Nessa perspectiva nos indagamos se a apropriação dos espaços de Educação Não Formal, especificamente os museus, pelos educadores, não seria uma maneira satisfatória para a formação de alunos mais motivados, curiosos e certos de que o conteúdo aprendido em sala de aula faça sentido no elo existente entre a EF e a ENF e, consequentemente, incrementar positivamente os índices evidenciados nas avaliações externas.

Frente a tal contexto, o presente capítulo tem como objetivo compreender os impactos previstos na exclusão cognitiva em massa discutida por Bourdieu (1989) e refletir sobre como a escola contemporânea pode reduzir a discrepância cultural por meio da visitação a museus. Sobre tal abordagem, Queiroz (2010, p. 451) afirma:

Em relação à metodologia educativa em museus, destaca-se na literatura desse campo a importância que se dá ao fato de que esses espaços sejam locais prazerosos, lúdicos, nos quais são valorizadas as 
emoções, que pela própria etimologia da palavra se liga às motivações, de tão reconhecida importância nos processos educativos. A partir dessa perspectiva, é muito comum o argumento de que o lúdico é algo que distingue a metodologia educativa utilizada nos museus da que é utilizada nas escolas. Efetivamente, trata-se de uma forma de simplificação do debate sobre as especificidades desses dois espaços educativos, pois em ambos essa perspectiva pode ser adotada em prol da aprendizagem, não havendo, no entanto, nenhuma obrigação ou mesmo conveniência para se ficar restrito a ela.

A exclusão cognitiva em massa, segundo Bordieu (1989), refere-se à cobrança de habilidades extraclasse solicitadas pelas aulas na $\mathrm{EF}$, evidenciando que os alunos cujos pais e famílias frequentam, por exemplo, aparelhos sociais como museus, zoológicos e exposições diversas detêm maior capital cultural.

\section{A Educação Básica Brasileira em Dados}

Tomemos como base de discussão os dados da Educação Básica Brasileira obtidos a partir da Prova Brasil/SAEB (INEP, 2018c) e os dados da Avaliação Internacional PISA (INEP, 2018b). Importante pontuar que muitos críticos indicam a pouca relevância de tal avaliação, pois as julgam excludentes e acreditam que não consigam refletir a realidade das escolas, uma vez que a maneira de avaliação é padronizada para todo território brasileiro e internacional, não considerando as singularidades das localidades. Não iremos aqui adentrar a esta discussão, visto que tais avaliações estão postas e sendo utilizadas para o estabelecimento de parâmetros de políticas públicas para direcionamento/redirecionamento da educação brasileira.

A primeira avaliação citada sempre é aplicada em anos ímpares, tendo seus resultados divulgados nos anos pares com o objetivo de avaliar os níveis de proficiência (aprendizagem) em Língua Portuguesa, com ênfase na leitura, e em Matemática, com foco na resolução de problemas. A avaliação é realizada com turmas finais de cada segmen- 
to, ou seja, quintos e nonos anos do Ensino Fundamental e terceiros anos do Ensino Médio (INEP, 2018c).

Quanto à avaliação PISA, esta é aplicada a cada três anos e tem como foco Leitura, Matemática e Ciências da Natureza. Em 2015, participaram do PISA 35 países membros da Organização para Cooperação e Desenvolvimento Econômico (OCDE) e 35 países parceiros. A avaliação é aplicada de forma amostral (aproximadamente 90 escolas do Brasil) para alunos a partir do sétimo ano do Ensino Fundamental que já tenham completado quinze anos de idade (INEP, 2018b).

Estão disponíveis e apresentaremos a seguir, dados da Prova Brasil/SAEB de 2017 e do PISA 2015, em particular com enfoque no Brasil, no Estado de Minas Gerais e na cidade de Uberaba. Vale ressaltar que, até 2018, nenhuma escola pública do município havia realizado a avaliação PISA. Em 2018, a Escola Municipal Professora Esther Limírio Brigagão, da cidade de Uberaba, Minas Gerais, fora escolhida para realizar tal avaliação. Os autores, enquanto gestores da referida escola, puderam perceber tratar-se de um processo transparente e idôneo e, dessa forma, tiveram a oportunidade de conhecer um pouco mais a fundo a dinâmica de uma avaliação tão renomada.

O boletim de desempenho dos alunos (INEP, 2018a), referente a 2017, classifica o percentual de alunos em níveis de proficiência, sendo para o $5^{\circ}$ ano dez ( 0 a 9) níveis em Língua Portuguesa e onze (0 a 10) em Matemática. No $9^{\circ}$ ano, Língua Portuguesa apresenta nove níveis (0 a 8 ) e Matemática dez níveis (0 a 9). No $3^{\circ}$ ano do Ensino Médio, Língua Portuguesa possui nove níveis ( 0 a 8 ) e Matemática onze níveis (0 a 10).

A análise da Distribuição Percentual dos Alunos por Nível de Proficiência apresentada no Boletim de Desempenho (INEP, 2018a) e organizada graficamente na Figura 01, possibilitou verificar que existe uma porcentagem significativa de alunos em situação crítica. 
Figura 1. Distribuição Percentual dos Alunos por Nível de Proficiência nos resultados da Prova Brasil/SAEB 2017, no Brasil e município de Uberaba/MG, para o $5^{\circ}$ ano e $9^{\circ}$ anos do Ensino Fundamental e $3^{\circ}$ ano do Ensino Médio (EM) para Língua Portuguesa (LP) e Matemática (M). Ainda não disponíveis dados para comparação nas turmas de Ensino Médio.

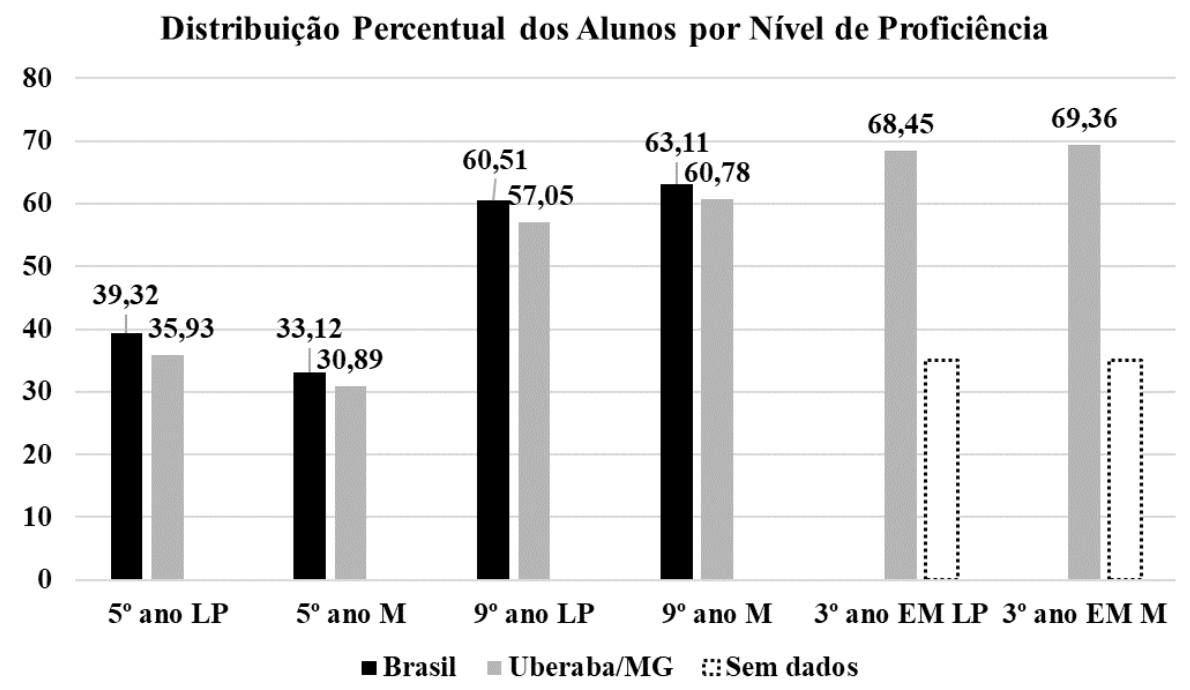

Fonte: INEP (2018a)

No $5^{\circ}$ ano, em Língua Portuguesa, o Brasil apresentou 39,32\% de alunos em situação crítica, e 33,12\% em Matemática. No $9^{\circ}$ ano, a situação é agravada sendo 60,51\% em Língua Portuguesa e 63,11\% em Matemática. Nesse documento são apresentados, para o $3^{\circ}$ ano do Ensino Médio, apenas os dados do município, não constando informações das esferas estadual e nacional. Quando analisamos os dados no município de Uberaba/MG, observamos que a cada finalização de etapa o percentual de alunos em situação crítica aumenta. Quanto ao PISA, o Brasil, frente aos setenta países participantes, está na $63^{\mathrm{a}}$ posição em Ciências, 59 a em Leitura e $65^{\mathrm{a}}$ em Matemática, o que indica a necessidade de melhoria da educação ofertada.

Tais dados nos fazem refletir o que está acontecendo com o nível de aprendizagem do nosso país e, acima de tudo, o que estamos fazendo para modificar tais dados, em busca de uma educação que tenha significado e seja igualitária. Seja educador ou não, fica a reflexão: $\mathrm{O}$ 
que estou fazendo para proporcionar aos meus alunos uma educação com equidade? E mais, quais alternativas podemos adotar na Educação Básica para que tais dados sejam positivamente regredidos?

\section{Pierre Bourdieu e a escola pública contemporânea}

A escola é, teoricamente, o primeiro lugar onde o conhecimento é "construído" de forma democrática, igualmente para todos os alunos. Pierre Félix Bourdieu (1930-2002), sociólogo francês, percebeu que o ensino não ocorre da mesma forma para todos os alunos como a escola faz parecer. Segundo ele, alunos pertencentes às classes sociais mais favorecidas trazem de berço uma herança chamada por ele de "capital cultural".

A cultura, para Bourdieu (1989), refere-se aos valores e significados que orientam e dão personalidade ao grupo social. Já capital cultural é uma metáfora criada pelo autor para explicar como a cultura em uma sociedade dividida em classes se transforma em uma espécie de moeda que as classes dominantes utilizam para acentuar as diferenças. A cultura se transforma em instrumento de dominação. Além disso, a classe dominante impõe às classes dominadas sua própria cultura, conferindo a ela um valor incontestável, fazendo crer que a cultura a ser propagada socialmente seja a sua. $\mathrm{O}$ capital cultural, segundo o autor, se expressa em três estados: o incorporado, adquirido com o convívio familiar, o objetivado, por meio do acesso aos bens culturais, e o institucionalizado, a partir das titulações.

Bourdieu (2001) percebeu essa dinâmica e a denominou "arbitrária cultural dominante", que nada mais é do que uma cultura se impor sobre a outra. Uma das mais importantes contribuições deste pensador para a educação foi transpor toda essa ideia para dentro da escola. Segundo ele, a escola dissimuladamente contribui para que a cultura dominante continue sendo transferida como tal, e dessa forma, favorece um aluno em detrimento de outros. Os desfavorecidos são justamente aqueles alunos que não tiveram acesso ao capital cultural, por 
meio da família (incorporado), pela falta de referenciais culturais considerados apropriados pela cultura dominante e pela baixa acessibilidade aos bens culturais (objetivado) como livros, pinturas, esculturas. Para a aquisição de capital cultural objetivado não basta acessar ou ad quirir os bens culturais, é necessário também se apropriar dos códigos para compreendê-los.

Portanto, os alunos não conseguem dominar os mesmos códigos culturais que a escola determina. $\mathrm{O}$ aprendizado para eles passa, então, a ser muito mais difícil. Bourdieu (2001) acredita que, assim, a escola marginaliza os alunos menos favorecidos e privilegia aqueles mais dotados de capital cultural.

Por isso o discurso de igualdade que a escola prega não funciona na prática. A escola não cobra dos alunos apenas o que foi ensinado, porém adiciona outras habilidades que são naturais para uns e estranhas para outros e, dessa maneira, acaba por enfatizar as diferenças. Os alunos que cresceram em culturas distintas ou que não apresentam amplo capital oriundo da cultura dominante se enganam e pensam que as dificuldades se dão pela "falta de inteligência". Um exemplo dessa dominação cultural nas escolas é a escolha das disciplinas consideradas mais importantes: é comum, por exemplo, Educação Física e Desenho não serem valorizadas. Assim a dominação de uma classe sobre a outra se mantêm.

$\mathrm{O}$ autor acreditava haver uma saída para toda essa violência simbólica, exercida inconscientemente pela escola. Bastava tornar explícito todo esse funcionamento velado da instituição.

\section{Os museus como fator propulsor da Educação Básica}

Ainsworth e Eaton (2010) distinguem a EF e a ENF, sendo a primeira intencional, organizada e estruturada, guiada por um currículo ou tipo de programa previamente definido. A ENF pode ou não ser intencional e guiada por uma instituição com finalidades educacionais próprias, podendo os museus serem ambientes que representam 
esta vertente educacional. Os autores deixam claro que existe valor em todos os espaços de aprendizagem, sendo que cada um têm sua importância na construção da identidade dos alunos. Além disso, a educação de qualidade é aquela que se pauta na pluralidade dos saberes, sendo o objetivo maior relacionar e investigar os laços entre EF e ENF. Bourdieu (1989) realiza uma séria crítica quanto ao fato da escola não reconhecer a pluralidade de saberes e/ou não trabalhar no sentido de diminuir a diferença de capital cultural entre os alunos. Desta forma, não se busca no trabalho com os alunos uma igualdade epistemológica entre os saberes populares e científicos, considerando-os como possíveis e válidos dentro de seus limites de atuação. Jacobucci (2010, p. 436437) concorda com os autores quando analisa tal temática em relação aos museus:

Ao vislumbrar um museu como uma alternativa para a prática pedagógica e como um local fértil para a aquisição do conhecimento científico atualizado, os professores demonstram interesse em relacionar um espaço não-formal de Educação à escola e à ação docente. É necessário entender o que os professores compreendem como cultura, visto que ao vivenciar experiências em espaços produtores de conhecimento diferentes da escola, os professores podem estabelecer inúmeras relações entre Ciência, produção do conhecimento científico, democratização científica e o ambiente escolar, dentre outras, que certamente propiciam a ampliação da cultura geral e científica.

Destaca-se que o processo de ensino e aprendizagem é um contínuo, ou seja, ocorre ininterruptamente, seja em casa, no trabalho ou na escola. Sobre este último, Ainsworth e Eaton (2010) destacam que processos educacionais se manifestam antes do período escolar e não cessam quando o indivíduo sai para visitas a campo, fora da escola. Assim, a ENF, por meio de visitas a museus, é uma proposta que busca o desenvolvimento e a criticidade do educando em prol da construção do conhecimento, sendo essa habilidade muito solicitada socialmente hoje. 
Fato é que o professor, ao fazer uma sondagem do conhecimento prévio dos alunos juntamente com o acompanhamento e a integração das diversas formas de exploração da interação museu-escola, colabora de forma decisiva com o processo de aprendizagem dos alunos. Esta é uma ação que norteia decisões, promove seleção de temas de estudo e, por conseguinte, define unidades de ensino e aprendizagem. O professor, ao utilizar os museus como entes maximizadores dos processos de ensino e aprendizagem, não apenas trabalha a questão de conceitos e conteúdos com os alunos, porém auxilia na compreensão de temas, como por exemplo, Ciência e Tecnologia, mas também fomenta consideravelmente o desenvolvimento intelectual do educando, em especial os que detêm uma bagagem econômica/cultural menos favorecida, ampliando seu capital cultural. Allard e colaboradores (1996), Cazelli (1992) e Almeida (1997) dialogam acerca dos museus como espaços educativos na perspectiva de que tais espaços são de suma importância para a socialização dos espaços externos à escola, além do desenvolvimento cognitivo e afetivo do visitante/educando.

Os museus possuem intencionalidade, pois têm como objetivo a complementação de modo a maximizar o processo de aprendizagem e desenvolver, de modo conjunto com a EF, particularmente as escolas, as potencialidades e o desenvolvimento. Sendo a aprendizagem um processo contínuo, Ainsworth e Eaton (2010), assim como Bourdieu (2001), criticam a fragmentação do conhecimento em disciplinas fechadas, sem que ocorra diálogo entre elas. Portanto, se faz necessária uma proposta integrada que culmine na alfabetização científica do educando.

Balizando o tema "Relação Museu e Escola" muitos diálogos, debates e até mesmo enfrentamentos devem ser realizados à medida que o objetivo geral de tal perspectiva é o de aliar de potencialidades de ambas as esferas, formal e não formal. Sobre os museus como espaços educativos, Alderoqui (1996, p. 6) menciona que: 
O visitante é o que materializa as propostas, sendo seus interesses e possibilidades os que marcam as condições e os limites da efetividade de uma exposição. Este tipo de exposição coexiste com o resto do museu, e nutre e retorna a ele de maneira constante. Ao organizar tal exposição, o problema é apresentar as ideias principalmente e ao mesmo tempo responder às necessidades evolutivas e emocionais do auditório ao qual é dirigida. Isso deve ser mantido em mente quando se trata de museus para crianças e jovens.

Alderoqui (1996) pontua que os museus são espaços divulgadores de conhecimento e pondera pontos convergentes e divergentes entre esses dois espaços, porém salienta que estes devem ser superados, visto que a continuidade e potencialidade de que dispõem os museus, instigando os alunos a questionarem e serem desbravadores, é surpreendente. Dujovne (1987) dialoga com Alderoqui (1996) e concorda que a visita oportuniza um bom trabalho curricular e sendo isto possível apenas por meio de atitudes parceiras e ao mesmo tempo crítico/investigativas, a fim de desvendar, com a parceria museu/escola, como ocorre tal acesso ao conhecimento.

Consideramos que os museus podem ampliar as possibilidades de uma formação contínua em sala de aula, na qual diferentes espaços educacionais participem da construção do conhecimento trabalhado com os alunos. Para tanto, vislumbramos as ações maximizadoras da EF nos espaços de ENF definidos pela Fundação Cultural e pela Prefeitura Municipal de Uberaba, Minas Gerais (PMU, 2006): Museu de Arte Decorativa - MADA, Museu do Zebu - Fundação Edilson Lamartine Mendes, Museu de Arte Sacra - MAS, Casa de Memórias e Lembranças Chico Xavier, Memorial Chico Xavier, Museu dos Dinossauros - MD, Museu Memória Viva e, Museu da Capela - Irmãs Dominicanas de Monteils.

Segundo Cazelli (2010), a distribuição geográfica de expressões culturais/científicas, como os museus, corrobora com a concepção de que a regiões geográficas nas quais se concentram os estratos sociais mais elevados detêm a maior concentração de tais aparatos. A autora 
realizou um estudo que contemplou estas questões na cidade do Rio de Janeiro/RJ e afirma:

Quando o que está em foco é a oferta de expressões culturais, a insuficiência e a concentração não equânimes do equipamento cultural afetam, em especial, as pessoas dos setores menos favorecidos do ponto de vista socioeconômico e cultural. Por exemplo, a cidade do Rio de Janeiro, apesar de ser um dos mais importantes centros culturais do país, não conseguiu ainda dar acesso à cultura de maneira equânime para seus habitantes. No tocante à distribuição de equipamentos associados à expressão da cultura cultivada (museu, centro cultural, teatro, cinema e biblioteca), nas áreas em que residem $75 \%$ da população (Ramos, Méier, Madureira, Ilha, Bangu, Campo Grande, Santa Cruz e Jacarepaguá), existem apenas 13\% dos equipamentos instalados. Já o Centro, São Cristóvão, Zona Sul, Tijuca, Vila Isabel e Barra, onde moram 25\% dos cariocas, dispõem de $87 \%$ da capacidade instalada (CAZELLI, 2010, p. 405).

Em Uberaba/MG, ainda não temos estudos relacionando a distribuição geográfica representada pela EF e ENF (nos espaços citados) e por esse motivo não trouxemos tais discussões. Mas é importante referendar tais dados abordados pela autora, uma vez que ela também apresenta dados que comprovam a diferença entre escolas da rede pública e privada do Rio de Janeiro/RJ quanto à visitação de alunos a museus (Tabela 1).

Tabela 1: Distribuição dos alunos, considerando o número de museus visitados ao longo da vida com a escola

\begin{tabular}{|c|c|c|c|}
\hline & & \multicolumn{2}{|c|}{ Rede de Ensino (em \%) } \\
\hline & & Privada & Municipal \\
\hline \multirow{6}{*}{$\begin{array}{l}\text { Número de museus vi- } \\
\text { sitados } \\
\text { (qualquer temática - } \\
\text { restrito) }\end{array}$} & Não visitou & 15 & 31 \\
\hline & Visitou 1 & 25 & 32 \\
\hline & Visitou 2 & 22 & 20 \\
\hline & Visitou 3 & 15 & 9 \\
\hline & Visitou 4 & 12 & 5 \\
\hline & Visitou 5 & 7 & 2 \\
\hline
\end{tabular}




\begin{tabular}{llll}
\hline & Visitou 6 & 3 & 1 \\
\cline { 2 - 4 } & Visitou 7 & 1 & - \\
\cline { 2 - 4 } & Visitou 8 & - & - \\
\hline Total & & 100 & 100 \\
\hline
\end{tabular}

Fonte: Cazelli (2010, p. 413)

Na Tabela 1, podemos observar que em um universo de 100 (cem) alunos entrevistados, 15 (quinze) da rede privada não visitaram nenhum museu, enquanto na rede pública este número salta para 31 (trinta e um) alunos. Quanto à quantidade de visitas que foram realizadas, ainda se nota que os alunos da rede privada visitam mais museus quando se comparam tais indicadores à visitação por alunos da escola pública.

Jacobucci (2010) considera que os professores têm um papel fundamental na visitação em museus, porém estes muitas vezes passaram por um modelo educacional no qual não tiveram acesso a estes espaços, portanto se sentem despreparados para conduzirem suas turmas durante visitas. A autora ainda reflete quanto à postura deste professor, que tem o papel de perceber a importância de tais espaços e a frequência a eles:

Quanto mais um professor frequentar espaços não-formais de Educação, mais relações poderá estabelecer entre esses espaços e os conteúdos científicos divulgados, uma vez que as características das mostras de divulgação científica englobam elementos similares na maioria dos ambientes não-escolares, como acervo biológico vivo ou acervo preservado, uso ou não de atividades interativas, utilização de recursos multimídia, dramatizações, jogos didáticos e monitoria. Com visitas frequentes a esses espaços, o professor poderá notar os elementos comuns e perceber que há, por trás da exposição, pessoas que organizam e mantém a mostra em função daquilo que acreditam ser o mais interessante, e financeiramente possível, para a divulgação ao público em geral (JACOBUCCI, 2010, p. 432). 
Uma das potencialidades da visitação a museus é refletir de uma maneira crítica como os conteúdos são trabalhados nos livros didáticos e como muitas notícias são veiculadas nos meios de comunicação de massa. Inicia-se, assim, o desenvolvimento da criticidade de alunos e professores em busca de seu protagonismo, que são estimuladas a partir de tais visitas. Acrescenta-se que o professor pode se sentir mais motivado a experimentar novas propostas metodológicas com o suporte de museus, pois podem perceber o quão importante e diferencial na vida de seus discentes tais espaços se estabelecem diminuindo, assim, a distância entre o Capital Cultural, na perspectiva de Bourdieu (1989), e os alunos, o que pode propiciar maior equidade na educação.

\section{Considerações Finais}

Os alunos que não apresentam o capital cultural objetivado e imposto pelas classes dominantes se deparam, ainda nos primeiros anos da Educação Básica, com a desvalorização de sua bagagem cultu$\mathrm{ral} /$ intelectual, pois esta não possui valor no que se refere ao conhecimento transposto para os currículos escolares. $\mathrm{O}$ capital cultural insuficiente e a violência simbólica que acomete tais alunos conduzem a um aprendizado inconsistente e incompreensível, fato que corrobora com o aumento dos índices de distorção idade/série e evasão. Uma das ações para superar tais obstáculos pode estar na parceria entre museus e escolas, na qual o aluno aprende não apenas conteúdos, mas também valores e vivências que possibilitarão a aquisição de capital cultural no estado objetivado.

Os professores, em geral, precisam internalizar a responsabilidade de desenvolvimento social e intelectual, tanto dos alunos quanto deles próprios, uma vez que o docente desprovido de capital cultural, ou aquele que não reconhece a potencialidade em adquiri-lo, muitas vezes encontra limites no desenvolvimento da criticidade e do protagonismo de nossos jovens. 
Defendemos aqui que a responsabilidade nesse sentido é muito maior para o professor de escolas públicas pois, além dos conteúdos ministrados, eles trabalham para fazer com que seus discentes de fato estejam no mesmo patamar cultural/intelectual de alunos que possuem uma condição social mais favorável, visto que não podemos atribuir tal função apenas à família, e não há como, dessa forma, impor que haja, por parte da família, uma formação nesse sentido aos seus filhos se eles próprios, enquanto genitores, não tiveram acesso a tais mecanismos.

Compreendemos, assim, que a visitação a museus, principalmente por meio de uma sólida parceria entre Secretarias de Educação/ Escolas/Museus, possa ampliar o acesso aos bens culturais, tanto por professores mas, principalmente, por alunos, para que assim as discrepâncias de capital cultural possam ser reduzidas, caminhando para maior equidade educacional almejando melhorias nos índices educacionais.

\section{Referências}

AINSWORTH, H.; EATON, S. Formal, non-formal and informal learning in the science, Calgary: Jacquelyn Clydesdale, 2010. 48 p. Disponível em: <http://files.eric.ed.gov/fulltext/ED511414.pdf. $>$ Acesso em: 02 jun. 2018.

ALDEROQUI, S. Museo y escuela: una sociedad posible. In.: Museos y Escuelas: socios para educar, $1^{\text {a }}$. Barcelona: Paidós Edición, 1996. p. 29-44. ALMEIDA, A. Desafios da relação museu-escola. Comunicação \& Educação, São Paulo, n. 10, p. 50-56, set./dez. 1997. DOI: <https://doi.org/10.11606/ issn.2316-9125.v0i10p50-56.>.

ALLARD, M. et. al. La visite au musée. In.: Réseau. Canadá, Décembre 1995/ Jan 1996.

BOURDIEU, P. O poder simbólico. Rio de Janeiro: Bertrand, 1989.

. Os três estados do capital cultural. In: NOGUEIRA, M. A.; CATA-

NI, A. (Orgs.) Escritos de educação. 3. ed. Petrópolis: Vozes, 2001, p. 73-79. 
CAZELLI, S. Jovens nos museus: quem são, aonde vão e com quem visitam? In: DALBEN, A.; DINIZ, J.; LEAL, L.; SANTOS, L. (org.). Convergências e tensões no campo da formação e do trabalho docente. Belo Horizonte: Autêntica, 2010, p. 402-426. Disponível em: $<\underline{\text { https://perdigital.files.wordpress.- }}$ com/2011/04/livro 5.pdf.> Acesso em: 29 mai. 2018.

. Alfabetização Científica e os Museus Interativos de Ciência. 1992.

173 f. Dissertação (Mestrado em Educação) - Departamento de Educação. Pontifícia Universidade Católica do Rio de Janeiro (PUC-Rio). Rio de Janeiro, 1992.

CONNOR, S. Cultura Pós-Moderna. São Paulo: Loyola, 1993.

DELL 'ISOLA, R. L. P. A interação sujeito-linguagem em leitura. In: MAGALHÃES, I. (org.). As múltiplas faces da linguagem. Brasília: UnB, 1996. p. 6975.

DUJOVNE, M. Propuestas para un anteproyecto de Museo de Ciencia y Técnica para chicos y jovenes en la ciudad de Buenos Aires, Buenos Aires, 1987, mimeografado.

GOULEMOT, J. M. Da leitura como produção de sentidos. In: CHARTIER, R. Práticas de leitura. São Paulo: Estação Liberdade, 1996.

GOHN, M. G. Educação não formal e cultura popular. São Paulo: Cortez, 2006.

JACOBUCCI, D. F. C. Professores em espaços não-formais de educação acesso ao conhecimento científico e formação continuada. In: DALBEN, A.; DINIZ, J.; LEAL, L.; SANTOS, L. (Org.). Convergências e tensões no campo da formação e do trabalho docente. Belo Horizonte: Autêntica, 2010, p. 426446. Disponível em: < https://perdigital.files.wordpress.com/2011/04/ livro_5.pdf.> Acesso em: 29 mai. 2018.

LEFFA, V. Aspectos da leitura: uma perspectiva psicolingüística. Porto Alegre Sagra: DC Luzzatto, 1996.

INEP. Instituto Nacional de Estudos e Pesquisas Educacionais Anísio Teixeira. Ministério da Educação. Boletim da Escola. Resultados Finais. 2018a. Disponível em: $<$ http://sistemasprovabrasil.inep.gov.br/provaBrasilResultados/.> Acesso em: 05 out. 2018. 
. Instituto Nacional de Estudos e Pesquisas Educacionais Anísio Teixeira. Ministério da Educação. Brasil no PISA 2015: Análises e reflexões sobre o desempenho dos estudantes brasileiros. 2018b. Disponível em: $<\underline{\mathrm{http}: / /}$ download.inep.gov.br/acoes internacionais/pisa/resultados/2015/ pisa2015 completo final baixa.pdf.> Acesso em: 05 out. 2018.

. Instituto Nacional de Estudos e Pesquisas Educacionais Anísio Teixeira. Ministério da Educação. Ministério da Educação. Prova Brasil/SAEB. 2018c. Disponível em: <http://download.inep.gov.br/educacao basica/saeb/ 2018/documentos/saeb documentos de referencia versao 1.0.pdf. $>$ Acesso em: 05 out. 2018.

PREFEITURA MUNICIPAL DE UBERABA (PMU). Fundação Cultural. Museus de Uberaba. (Cartilha). Uberaba: Prefeitura Municipal de Uberaba, 2006.

QUEIROZ, G. R. P. C. Acesso ao conhecimento científico pela mídia e ambientes não escolares em uma nova situação educacional. In: DALBEN, A.; DINIZ, J.; LEAL, L.; SANTOS, L. (Orgs.). Convergências e tensões no campo da formação e do trabalho docente. Belo Horizonte: Autêntica, 2010, p. 447465. Disponível em: <https://perdigital.files.wordpress.com/2011/04/ livro 5.pdf.> Acesso em: 29 mai. 2018. 
